\title{
Rapid identification of Brucella sepsis/ osteomyelitis in a 6-year old febrile patient with matrix-assisted laser desorption/ ionization time-of-flight mass spectrometry directly from positive blood culture: a case report
}

Junfei Guo, Weiming Lai, Biting Li, Lingling Tang, Yongbing Wu, Yasha Luo, Chengyi Liu, Weiming Lu and Xiaoping $\mathrm{Mu}^{*}$

\begin{abstract}
Background: Brucella is high-consequence pathogen and one of the most common seen laboratory- acquired infection pathogens. Quick and accurate detection of the pathogen will be of great important to reducing laboratory- acquired infection. Traditional biomedical reaction based method is time consumption, and mass spectrometry based method greatly reduces time consumption in pathogen identification. In the case presented here, we shared our experience in identification of Brucella directly from positive blood culture with mass spectrometry based method.
\end{abstract}

Case presentation: The patient is a 6-year boy with a history of three weeks fever accompanied with sweating and a pain at right patella. The patient also has a history of thalassemia and blood transfusion was performed previously admitted to our hospital. Two bottles of marrow culture and one bottle of blood culture were positive, and direct mass spectrometry from positive culture material revealed Brucella infection within $1 \mathrm{~h}$.

Conclusion: Clinical characters and laboratory findings of the patient presented here might help clinician in nonendemic region to made suspected brucellosis diagnose. Our experience in rapid identification of Brucella from positive blood culture with MALDI-TOF SP could help preventing laboratory-acquired infection of Brucella.

Keywords: Brucella, Brucellosis, MALDI-TOF SP, Rapid identification

\section{Background}

As a wide spread zoonosis, brucellosis remains a public health problem around the word. Brucella spp. is the causative pathogen of the disease, and B.melitensis and B. abortus are the most common isolated species [1]. The diagnosis of the disease depends on the isolation of the pathogen, which needs several days with previous biochemical reaction based identification methods. As no

\footnotetext{
* Correspondence: muxiaoping710@126.com

Clinical laboratory department of Guangdong Women and Children's hospital, Xiaoping Mu, No.521 Xingnan Road, Panyu 511400, Guagnzhou, China
}

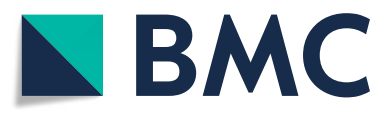

(c) The Author(s). 2019 Open Access This article is distributed under the terms of the Creative Commons Attribution 4.0 International License (http://creativecommons.org/licenses/by/4.0/), which permits unrestricted use, distribution, and reproduction in any medium, provided you give appropriate credit to the original author(s) and the source, provide a link to the Creative Commons license, and indicate if changes were made. The Creative Commons Public Domain Dedication waiver (http://creativecommons.org/publicdomain/zero/1.0/) applies to the data made available in this article, unless otherwise stated.

enough precautions were paid to these high-consequence pathogens at routine clinical laboratory especially in non-endemic areas, it causes one of the most prominent laboratory-acquired infections around the world $[2,3]$. Thus quick and correct identification of the pathogen will be of great interest in reducing the laboratory-acquired infections of Brucella [4, 5].

Here, we shared our experience in a recent case of brucellosis. We identified the pathogen directly from positive blood and marrow culture with Bruker MALDI-TOF within $2 \mathrm{~h}$ after blood culture became positive. It's of great interest considering that our blood 
culture bottle is BACT/ALERT ${ }^{\circ} \mathrm{PF}$ with activated charcoal, which is considered not suitable for directly identified with MALDI-TOF. We also shared our two-step centrifugation ethanol/formic acid tube extraction method, which we think will be of great help in case of lacking of MBT Sepsityper Kit or in the situation like us use Bact/ALERT 3D blood culture system.

\section{Case presentation}

A 6-year old boy with a history of 3-week fever (unknown origin) accompanied by weight lost $(-2.5 \mathrm{Kg})$ was admitted to pediatric department of Guangdong Women and Children Hospital. The boy experienced a 3 -week of fever and sweating, which mainly happened at night and peaked at $40.3 \mathrm{C}$ degree. A pain at right patella was also reported. What's more, the boy had a history of thalassemia with hemoglobin fluctuating between 95 and $100 \mathrm{~g} / \mathrm{L}$. Blood transfusion and antibiotic treatment (Cefperazone-Sulbactam, Azithromycin and piperacillin-sulbactam) were conducted at a local hospital before admitting to our hospital, but intermittent fever continued. On admission, physical examination and laboratory detection were conducted. All the physical examinations were normal, except for diffuse enlargement of mesenteric lymph nodes. Laboratory test indicated a drop of white blood cell $\left(3.33^{*} 10^{\wedge} 9 / \mathrm{L}\right.$, $\mathrm{N}, 26.7 \% \mathrm{~L}, 64.65)$ and hemoglobin $(71 \mathrm{~g} / \mathrm{L})$, and increase of erythrocyte sedimentation rate (ESR, $25 \mathrm{~mm} / \mathrm{h}$ ) and ferroprotein (FER, $1669 \mathrm{ng} / \mathrm{ml}$ ). Slight increase of ALT $(105 \mathrm{U} / \mathrm{L})$ and AST $(145 \mathrm{U} / \mathrm{L})$ and significant increase of LDH (2082 U/L) were also observed. The serum level of high sensitive c-response protein (hsCRP) was normal $(6.81 \mathrm{mg} / \mathrm{L})$, and the level of procalcitonin (PCT) was slight increase $(0.16 \mathrm{ng} / \mathrm{ml})$. At the time of admission, two sets of blood culture and two sets of bone marrow culture were obtained. Two marrow culture presented positive 2.6 days post obtained, and one set of blood culture present positive 3.6 days post obtained, while the other set of blood culture remained negative ( 5 days).

\section{Pathogen identification directly form positive blood culture with MALDI-TOF}

Gram stain of smear prepared from positive blood culture was done, but no bacteria were seen throughout the slide (three of our laboratory workers viewed the slide). MALDI-TOF analysis directly from positive blood culture was conducted with two-step centrifugation method as previous reported with some modification. The procedures were as follow: $1.5 \mathrm{ml}$ of positive blood/marrow culture was transferred to $1.5 \mathrm{ml}$ centrifugation tube, and then centrifuged for $2 \mathrm{mins}$ at $500 \mathrm{rpm}$ (eppendorf, centrifuge 5945R); the supernatant was transferred to a new tube, centrifuged for $2 \mathrm{mins}$ at $12,000 \mathrm{rpm}$ and discarded the supernatant; re-suspended the precipitation with $1 \mathrm{ml}$ sterile water, and centrifuged for $2 \mathrm{mins}$ at $12,000 \mathrm{rpm}$; the final precipitation was proceeded with standard methane acid extraction method. MALDI-TOF analysis yielded none reliable identification while searching standard database (IVD BD5989). Considering the clinical characteristic and laboratory findings of the patient, as well as long time consumption before blood/ marrow culture became positive, we reanalyzed the spectrum with self-construct database (provided by the supplier) containing four isolates of Brucella. The result demonstrated that the spectrum hit two of four Brucella isolates with score of 1.90 and 1.88, respectively. Suspected Brucella infection was considered, and all the biomaterials of the patient were sealed immediately. A communication was made with clinician for bio-safety and epidemiology purposes.

\section{Pathogen confirmation with isolations by MALDI- TOF and Vitek2 compact system}

All the isolates separated from positive blood/marrow culture presented morphology of Brucella. We used on-plate formic acid method to prepare the sample for MALDI-TOF analysis. Four reliable identifications of Brucella with score ranging from 2.3 to 2.4 were obtained. As our self-construct database could not identify the Brucella to species level, we re-identified the isolates with Vitek2 Compact system with GN card, and the results demonstrated that the isolates were all $B$. melitensis with 98\% confidences level. Definite Brucella infection was confirmed, and the patient was transferred to specialized hospital for infectious diseases according to relative law.

\section{Discussion and conclusions}

In the case presented here, we shared our experience in the use of MALDI-TOF for rapid identification of Brucella infection directly from positive blood culture (Fig. 1). Laboratory workers are at high risk of getting laboratory-acquired infection of Brucella via direct contact or exposure to aerosol [3-5]. Quick and correct identification will be great help in reducing thus infection. Compared with our previous reported case [6], we saved almost $48 \mathrm{~h}$ from positive blood culture to correct identification of pathogen. It's of great interest considering that our hospital located at non-endemic area and no enough precautions are paid to thus high-consequence pathogen at our biosafety level (BSL)2 laboratory. Our rapid identification of the pathogen avoided more individuals exposed to the high-risk pathogen.

Many previous studies reported using MALDI-TOF for rapid identification of the bacteria from positive blood culture [7-9]. In many cases, they used BACTEC ${ }^{\mathrm{m}}$ FX system for blood culture and use MBT Sepsityper Kit to prepare the sample for MALDI-TOF analysis. Positive blood culture with BACT/ALERT ${ }^{\circ} \mathrm{PF}$ is considered not suitable for direct MALDI-TOF analysis as activated 


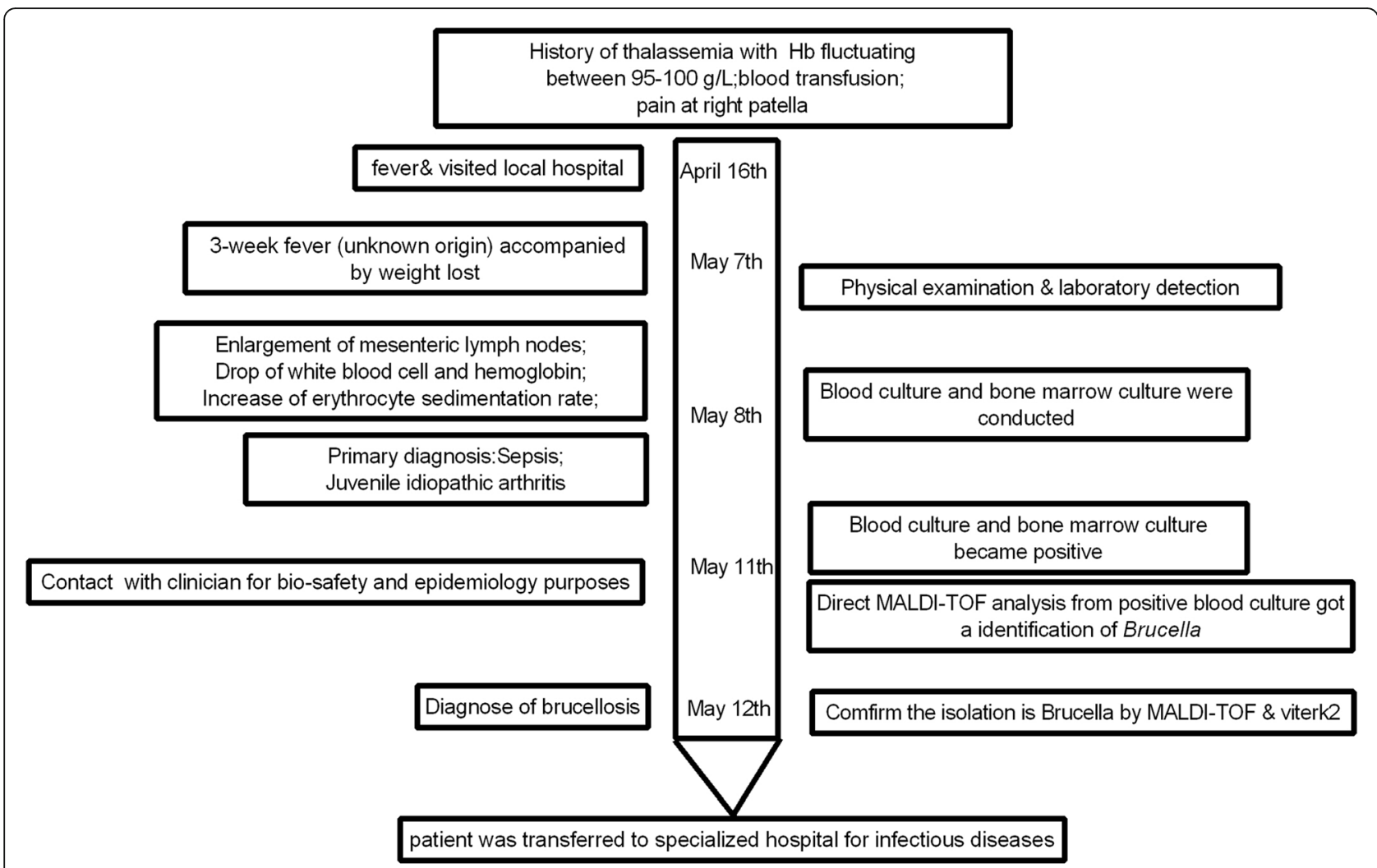

Fig. 1 The timeline of our case The showing picture is the timeline of the reported case. Above the arrow is the medical history of the patient, the arrow represents the time course, the left side is the symptoms, signs and diagnosis along time, the right side is the course of pathogen identification

charcoal may affect the analysis. In an on-going project, we find that two-step centrifugation ethanol/formic acid tube extraction method could yield good identification results, and the case presented here is an example. As many hospitals use Bact/ALERT 3D system for blood culture, our experience might help in rapid identification of the pathogen with Bruker MALDI-TOF while using Bact/ALERT 3D blood culture system.

In this case, we found that good quality spectrums were obtain both from positive blood culture or isolates, but yield no reliable identification while searching standard database (IVD BD5989) only. In fact Bruker provides security relevant database, but it's restricted in some countries like China due to the local law. A self-construct database (provided by the supplier) helps us rapid identifying the pathogen. This self-construct database contains the spectrums of four Brucella isolates (two B.melitensis and two B. abortus). It's of great help in identification less-common isolated pathogens using such self-construct database.

As the symptoms of brucellosis are nonspecific (mainly fever accompanied by sweating), it's difficult to diagnosis of the disease from clinical sign only. Our patient visit a local hospital but the disease did not diagnose, and experienced antibiotic treatment was conducted. This may the reason why one of the blood cultures remained negative.
Our rapid identification of the pathogen leads to prompt diagnosis of the disease. Combine with our previous reported case of brucellosis [6], we think that cautions should be paid to the unknown origin long-term fever patient with following laboratory results: A drop of WBC (dominant with lymphocyte), unchanged or slightly increase hsCRP or PCT level, slightly increase of ESR, anemia and sometimes enlargement of local lymph nodes. Directly identification of the pathogen from positive blood culture of these patients might help diagnose the disease ahead of time, which will be of great interest in preventing the spread of the disease in case of brucellosis.

In all, a good combination of blood culture and MALDI-TOF analysis will be of great help in preventing laboratory-acquired infection of high-consequence pathogens, such as Brucella. Our experience might help those with Bruker MALDI-TOF mass spectrometry but using Bact/ALERT 3D blood culture system or those without MBT Sepsityper Kit at hand.

\footnotetext{
Abbreviations

FER: Ferroprotein; hsCRP: High sensitive c-response protein; MALDI-TOF SP: Matrix-assisted laser desorption/ionization time-of-flight mass spectrometry; PCT: Procalcitonin
}

Acknowledgements

Not applicable. 
Funding

No funding to be declared.

\section{Availability of data and materials}

All data generated or analyzed during this study are included in this published manuscript.

\section{Authors' contributions}

G-JF, Li-BT and L-WM performed the majority of the pathogen identification, T$\mathrm{LL}, \mathrm{W}-\mathrm{YB}$ and $\mathrm{L}-\mathrm{YS}$ collected the case clinical data; M-XP drafted the manuscript, and participated in the design of the study; L-CY and L-WM critically reviewed the manuscript. All of the authors read and approved the final manuscript.

\section{Ethics approval and consent to participate}

This research was carried out according to the principles of the Declaration of Helsinki and was approved by the Ethics Committees of the National Institute for Communicable Disease Control and Prevention and the Chinese Center for Disease Control and Prevention (No.ICDC-2014005). The subjects consented to participate and no animal work was carried out as part of this study.

\section{Consent for publication}

Parental written informed consent to publish this information was obtained from study participants.

\section{Competing interests}

None conflict of interest to be declared.

\section{Publisher's Note}

Springer Nature remains neutral with regard to jurisdictional claims in published maps and institutional affiliations.

\section{Received: 6 July 2018 Accepted: 1 March 2019}

Published online: 11 March 2019

\section{References}

1. Stratton C. Manual of clinical microbiology, 9th edition:manual of clinical microbiology, vol. 46. 9th ed; 2008.

2. Sam IC, Karunakaran R, Kamarulzaman A, Ponnampalavanar S, Syed Omar SF, Ng KP, Mohd Yusof MY, Hooi PS, Jafar FL, Abubakar S. A large exposure to Brucella melitensis in a diagnostic laboratory. J Hosp Infect. 2012;80(4): $321-5$.

3. Singh K. Laboratory-acquired infections. Clin Infect Dis. 2009:49(1):142-7.

4. Becker SL, Zange S, Brockmeyer M, Grun U, Halfmann A. Rapid MALDI-TOFbased identification of Brucella melitensis from positive blood culture vials may prevent laboratory-acquired infections. J Hosp Infect. 2018.

5. Traxler RM, Lehman MW, Bosserman EA, Guerra MA, Smith TL. A literature review of laboratory-acquired brucellosis. J Clin Microbiol. 2013;51(9):3055-62.

6. Junfei Guo WL, Yongbing W, Xiaoping M. Eating goat's placenta and brucellosis caused by Brucella melitensis. Int J Clin Exp Med. 2018;11(3):8.

7. Barnini S, Ghelardi E, Brucculeri V, Morici P, Lupetti A. Rapid and reliable identification of gram-negative bacteria and gram-positive cocci by deposition of bacteria harvested from blood cultures onto the MALDI-TOF plate. BMC Microbiol. 2015;15:124.

8. Chen Y, Porter V, Mubareka S, Kotowich L, Simor AE. Rapid identification of Bacteria directly from positive blood cultures by use of a serum separator tube, smudge plate preparation, and matrix-assisted laser desorption ionization-time of flight mass spectrometry. J Clin Microbiol. 2015;53(10): 3349-52.

9. Jakovljev A, Bergh K. Development of a rapid and simplified protocol for direct bacterial identification from positive blood cultures by using matrix assisted laser desorption ionization time-of- flight mass spectrometry. BMC Microbiol. 2015;15:258

\section{Ready to submit your research? Choose BMC and benefit from:}

- fast, convenient online submission

- thorough peer review by experienced researchers in your field

- rapid publication on acceptance

- support for research data, including large and complex data types

- gold Open Access which fosters wider collaboration and increased citations

- maximum visibility for your research: over $100 \mathrm{M}$ website views per year

At $\mathrm{BMC}$, research is always in progress.

Learn more biomedcentral.com/submissions 